\title{
RELATIONSHIP OF INTERNET ADDICTION WITH DEPRESSION AND ACADEMIC PERFORMANCE IN INDIAN DENTAL STUDENTS
}

\author{
SANDEEP KUMAR ${ }^{1}$, AMIT KUMAR ${ }^{2}$, BHUMIKA BADIYANI ${ }^{2}$, \\ SIDDHARTH KUMAR SINGH ${ }^{3}$, ANJALI GUPTA ${ }^{4}$, MOHAMMED B ISMAIL ${ }^{5}$
}

\author{
${ }^{1}$ Department of Public Health Dentistry, Dental Institute, RIMS, Ranchi, India \\ ${ }^{2}$ Department of Public Health Dentistry, Sarjug Dental College, Bihar, India \\ ${ }^{3}$ Department of Oral Medicine and Radiology, Saraswati Dental College and \\ Hospital, Lucknow, India \\ ${ }^{4}$ Department of Dentistry, Saraswati Medical College, Unnao, Uttar Pradesh, \\ India \\ ${ }^{5}$ Department of Periodontology, GDCRI, VIMS, Ballari, Karnataka, India
}

\begin{abstract}
Background and aims. Internet addiction (IA) has negative consequences on the mental health and affects daily activities. This study was conducted with the aim to assess the prevalence of Internet addiction among dental university students and to determine if there is any relationship of excessive Internet use with depression and academic performance among students.

Methods. This was a cross sectional study which included 384 dental students from different academic years. A questionnaire was prepared that collected information on demographic characteristics, pattern of Internet use, duration of use, and most common mode of Internet access. Internet addiction was assessed using Youngs Internet Addiction test. Depression was assessed using Becks depression inventory [BDI-1].

Results. The prevalence of Internet addiction and depression was found to be $6 \%$ and $21.5 \%$ respectively. The first year students showed the highest mean Internet addiction (17.42 12.40$)$ score. Chatting was the main purpose for Internet use. Logistic regression analysis showed that individuals who were depressed (Odds Ratio $=6.00, p$ value $<0.0001 *$ ) and scored less than $60 \%$ marks (Odds Ratio $=6.71$, p value $<0.0001 *$ ) were more likely to be addicted to Internet.

Conclusion. The addiction to internet has negative impact on mental health and academic performance. These high risk group students should be identified and psychological counseling should be provided.
\end{abstract}

Keywords: Internet addiction, depression, academic performance, counseling, India

\section{Background and aim}

There has been a rapid increase in the use of Internet by all sections of the society. It is predicted that there are more than 600 million users of the Internet worldwide [1]. The Pathological Internet use [PIU] or Internet addiction [IA] is a common problem found in adolescents and University students as reported by various studies $[2,3,4]$.

Manuscript received: 29.03.2017

Received in revised form: 30.10 .2017

Accepted: 09.11.2017

Address for correspondence: drsandeep40@gmail.com
Internet addiction has been defined as an individual's uncontrollable use of the Internet that has created psychological, social, and/or work problems in one's life. [5].

The prevalence of Internet addiction among youth may vary from $1.98 \%$ to $35.8 \%$ [6]. Several factors on the conceptual and methodological levels have been proposed to explain the discrepancy among these findings, such as the use of different instruments, diagnostic criteria, samples, and research designs [7]. The university students are the major 
Internet users, needing to use the Internet for educational purposes, accessing virtual libraries, conducting research studies, and recreational activities $[2,8]$. Thus, they are more prone to Internet addiction because of ease of access to the internet and absence of self-control [9].

Despite the benefits of Internet use, the excessive use of internet can have negative consequences too. A number of studies have reported that Internet use is associated with greater depression $[10,11,12]$. Besides these, researchers have also found that adolescents' addiction to the Internet has resulted in many negative consequences including academic failure, poor family relationships, impaired social functioning, emotional problems, and psychiatric problems $[13,14]$.

In recent years Internet addiction has become the most significant International mental health problem and needs special attention [2,9]. In India also, there has been a rise in the use of Internet use by all age groups especially adolescents and university students. There has been limited study carried out to check the association between Internet addiction, depression and academic performance in University students. Hence, this study was carried out to assess the prevalence of Internet addiction among dental university students and to determine if there is any relationship of excessive Internet use with depression and academic performance among University students.

\section{Methods}

This was a descriptive cross sectional study carried out in a private dental teaching institution in Indore City, Central India. The study was carried out in the first semester of the academic year 2015-16. All the students from $1^{\text {st }}$ year to Internship were included in the study. A total of 384 students from different academic years were included in the final analysis. A total of 73 students from 75 admitted students from 1st year, 73 students from a total of 73 from second year, 69 of 70 students from third year, 69 students of 69 from final year and 65 students from a total number of 68 students from Interns batch were included in the study. An ample response rate $(>90 \%)$ was achieved from each academic year and thus the total absenteeism of six students from a total number of 390 students had a negligible influence on the results.

The study protocol was reviewed by the Ethical committee of related institution and was granted ethical clearance. The study objectives were explained to the participants and a written informed consent was obtained from all the students. All the students who were willing to participate signed the informed consent and present on the day of conduct of the study were included in the study. The students who were absent on the day of conduct of study and not willing to participate were excluded.

A pilot study was conducted to determine the sample size. G*Power 3.1 statistical software was used for sample size calculation. Based upon the findings of the pilot study and keeping the power of the study at $80 \%$, a sample size of 325 was needed. However, to overcome the problem of attrition and incomplete questionnaire and also to improve the power of the study, a total of three hundred eighty four students from different professional years were included in the analysis.

Internet addiction was assessed using Youngs Internet addiction test [15]. Previous studies have shown that Internet addiction test has good internal consistency reliability [11] and face and construct validity [16]. The Internet addiction test consists of 20 items on a 5 point Likert scale. The Total score ranges from 20-100. Scores greater or equal to fifty indicates Internet addiction [2].

The Becks depression Inventory [BDI-1] was used to measure depression. The questionnaire comprises 21 items that assess depression symptoms and attitudes, including pessimism, sense of failure, self-dissatisfaction, guilt, selfdislike, suicidal ideas, social withdrawal, indecisiveness, body image change, insom $\neg$ nia, fatigability, weight loss, somatic preoccupation, and loss of libido in the week preceding administration. The items are rated on a 4-point Likert scale, ranging from 0 to 3 . The cut-off point between having depression and not having depression is a score of 10 [17].

In addition, the questionnaire also collected information on demographic characteristics pattern of Internet use and duration of use. The academic performance was assessed on the basis of the percentage of marks obtained in previous University exams. As per academic grading in India, a student securing more than $60 \%$ marks is classified into first division category (good academic performance). For the sake of statistical convenience, the academic performance was dichotomized into $>60 \%$ marks (good academic performance) and $\leq 60 \%$ marks (Average / Regular performance)

Data were collected during students' classes. The Interns were approached in their respective clinical postings. The students were asked to fill the proforma in the classroom under the supervision of trained investigator. Any doubts arising during filling of the questionnaire were solved by the investigator himself. The students were not permitted to confer with each other. After 20 minutes the questionnaire were collected and any incomplete forms were asked to be completed. The response rate varied from 90-95\% in different professional years.

Data were analyzed using SPSS v 20. Descriptive statistics were performed. Logistic regression analysis was performed to identify the predictors for Internet addiction. $\mathrm{p}$ value $<0.05$ was considered statistically significant.

\section{Results}

The study was carried out on 384 dental students. The mean age of the study population was found to be $21.19 \pm 1.93$. Majority of the students weres females $(87.1 \%)$ and unmarried (98.9\%) (Table I). 
The overall mean Internet addiction score was found to be $13.87 \pm 11.90$. The 1 st year students $(17.42 \pm 12.40)$ showed the highest Internet addiction score followed by 4th year $(15.65 \pm 10.06)$. The third year students showed the lowest Internet addiction score (9.62 \pm 7.88$)$. A significant difference was observed in the mean Internet addiction score between different years of dental students.

The prevalence of Internet addiction was found to be $6 \%$ in the study population. No significant differences ( $p$ value $=0.091$ ) were observed between the prevalence of Internet addicted students with different academic years (Table II).

The mean depression score was found to be $11.27 \pm 8.37$. A significant difference ( $p$ value $<0.0001$ ) was observed in the mean depression score with students of different professional years of dental studies. The 4th year students $(15.34 \pm 11.86)$ showed the maximum depression score whereas 2 nd year students $(9.30 \pm 5.64)$ showed least depression score.

The overall prevalence of depression was found to be $21.50 \%$. The 3 rd year students $(36.20 \%)$ and 4 th year students $(31.90 \%)$ showed significantly higher ( $p$ value $=0.013$ ) prevalence of depression than other professional years of dental studies (Table III).

The majority of the students were using Internet for the purpose of chatting (38.70\%) and social networking $(27.90 \%)$. A larger number of students were accessing Internet through their mobile phones $(65.0 \%)$ and were using Internet for more than 5 years $(61.0 \%)$. Nearly $80 \%$ of the students obtained more than 60 percent marks in their previous university exams (Table IV).

A bivariate analysis was performed to identify the factors that were strongly associated with Internet addiction in dental students. The academic performance and mental status were strongly associated with Internet addiction. It was found that there was a significant difference ( $\mathrm{p}$ value $<0.0001^{*}$ ) observed in the mental status of the students $(17.3 \%)$ who were addicted to Internet than not-addicted students $(2.90 \%)$. Also, students who scored less than $60 \%$ marks $(18.60 \%$ ) were significantly (p value $<0.0001 *)$ more addicted to Internet than those who scored over $60 \%$ marks. (Table V)

Logistic regression analysis was performed to identify the strength of association. It was found that depression status and academic performance was strongly affected with Internet addiction. The individuals who were depressed $\left(\mathrm{OR}=6.00\right.$, $\mathrm{p}$ value $\left.<0.0001^{*}\right)$ and individuals who scored less than $60 \%$ marks $\left(\mathrm{OR}=6.71\right.$, $\mathrm{p}$ value $\left.<0.0001^{*}\right)$ were nearly six times more likely to be addicted to Internet than secure/ not-depressed student (Table VI).

Table I. Demographic characteristics of the study population.

\begin{tabular}{|c|c|c|c|c|c|c|c|}
\hline Variables & Categories & $\begin{array}{l}1^{\text {st }} \text { year } \\
\text { Number }(\%)\end{array}$ & $\begin{array}{l}2^{\text {nd }} \text { year } \\
\text { Number }(\%)\end{array}$ & $\begin{array}{l}3^{\text {rd }} \text { year } \\
\text { Number (\%) }\end{array}$ & $\begin{array}{l}4^{\text {th }} \text { year } \\
\text { Number }(\%)\end{array}$ & $\begin{array}{l}\text { Interns } \\
\text { Number (\%) }\end{array}$ & $\begin{array}{l}\text { Total } \\
\text { Number (\%) }\end{array}$ \\
\hline \multirow[t]{2}{*}{ Age } & $\leq 21$ years & $70(95.9 \%)$ & $65(89 \%)$ & $45(65.2 \%)$ & $21(30.4 \%)$ & $04(6.2 \%)$ & $205(58.7 \%)$ \\
\hline & $>21$ years & $03(4.1 \%)$ & $08(11 \%)$ & $24(34.8 \%)$ & $48(69.6 \%)$ & $61(93.8 \%)$ & $144(41.3 \%)$ \\
\hline \multirow[t]{2}{*}{ Gender } & Male & $15(20.5 \%)$ & $08(11 \%)$ & $06(8.7 \%)$ & $04(5.8 \%)$ & $12(18.5 \%)$ & $45(12.9 \%)$ \\
\hline & Female & $58(79.5 \%)$ & $65(89 \%)$ & $63(91.3 \%)$ & $65(94.2 \%)$ & $53(81.5 \%)$ & $304(87.1 \%)$ \\
\hline \multirow[t]{2}{*}{ Marital status } & Married & $0(0 \%)$ & $01(1.4 \%)$ & $01(1.4 \%)$ & $01(1.4 \%)$ & $01(1.5 \%)$ & $04(1.1 \%)$ \\
\hline & Unmarried & $73(100 \%)$ & $72(98.6 \%)$ & $68(98.6 \%)$ & $68(98.6 \%)$ & $64(98.5 \%)$ & $345(98.9 \%)$ \\
\hline
\end{tabular}

Table II. Mean Internet addiction score and distribution according to year of study.

\begin{tabular}{llll}
\hline Year of study & $\begin{array}{l}\text { Internet Addiction score } \\
\text { (Mean } \pm \text { SD) }\end{array}$ & $\begin{array}{l}\text { Addicted } \\
\text { Number (\%) }\end{array}$ & $\begin{array}{l}\text { Not-addicted } \\
\text { Number (\%) }\end{array}$ \\
\hline 1st year & $17.42 \pm 12.40$ & $6.0(8.2 \%)$ & $67.0(91.80 \%)$ \\
\hline 2nd year & $13.91 \pm 10.31$ & $3.0(4.1 \%)$ & $70.0(95.90 \%)$ \\
\hline 3rd year & $9.62 \pm 7.88$ & $2.0(2.9 \%)$ & $67.0(97.10 \%)$ \\
\hline 4th year & $15.65 \pm 10.06$ & $2.0(2.9 \%)$ & $67.0(97.10 \%)$ \\
\hline Interns & $12.46 \pm 16.27$ & $8.0(12.3 \%)$ & $57.0(87.70 \%)$ \\
\hline Total & $13.87 \pm 11.90$ & $21.0(6.0 \%)$ & $328.0(94.0 \%)$ \\
\hline p value & $<0.0001 * a$ & $0.091 \mathrm{~b}$ & \\
\hline
\end{tabular}

Statistical test applied: ${ }^{a}$ Kruskal-Wallis test; ${ }^{b}$ Chi square test

*Indicates statistical significant difference at $\mathrm{p} \leq 0.05$. 
Table III. Mean Depression score and distribution according to year of study.

\begin{tabular}{llll}
\hline Year of study & Depression score $($ Mean \pm SD) & Depressed Number $(\%)$ & Secure/Not depressed Number (\%) \\
\hline 1st year & $10.13 \pm 07.62$ & $9.0(12.30 \%)$ & $64.0(87.70 \%)$ \\
\hline 2nd year & $09.30 \pm 05.64$ & $8.0(11.0 \%)$ & $65.0(89.0 \%)$ \\
\hline 3rd year & $11.28 \pm 06.38$ & $25.0(36.20 \%)$ & $44.0(63.80 \%)$ \\
\hline 4th year & $15.34 \pm 11.86$ & $22.0(31.90 \%)$ & $48.0(68.10 \%)$ \\
\hline Interns & $10.43 \pm 07.92$ & $11.0(16.90 \%)$ & $54.0(83.10 \%)$ \\
\hline Total & $11.27 \pm 08.37$ & $75.0(21.50 \%)$ & $274.0(78.50 \%)$ \\
\hline p value & $<0.0001 * \mathrm{a}$ & $0.013 * \mathrm{~b}$ & \\
\hline
\end{tabular}

Statistical test applied: ${ }^{\mathrm{a} K r u s k a l-W a l l i s ~ t e s t ; ~}{ }^{\mathrm{b}} \mathrm{Chi}$ square test

*Indicates statistical significant difference at $\mathrm{p} \leq 0.05$.

Table IV. Pattern of Internet use and academic performance of the study population.

\begin{tabular}{lll}
\hline Variables & Categories & Number (Percentage) \\
\hline Main Purpose of Internet use & Chatting & $136.0(38.70 \%)$ \\
\cline { 2 - 3 } & Social networking & $98.0(27.90 \%)$ \\
\cline { 2 - 3 } & E mail & $45.0(12.80 \%)$ \\
\cline { 2 - 3 } & Entertainment & $34.0(9.70 \%)$ \\
\cline { 2 - 3 } & Surfing website & $9.0(2.60 \%)$ \\
\cline { 2 - 3 } & Academic activity & $27.0(7.70 \%)$ \\
\hline Duration of Internet use & $\leq 5$ years & $136.0(39.0 \%)$ \\
\cline { 2 - 3 } & $>5$ years & $213.0(61.0 \%)$ \\
\hline Primary method of access & Mobile phones & $227.0(65.0 \%)$ \\
\cline { 2 - 3 } & Personal computers & $48.0(13.60 \%)$ \\
\cline { 2 - 3 } & Internet cafe & $9.0(2.60 \%)$ \\
\cline { 2 - 3 } & University computer lab & $70.0(20.1 \%)$ \\
\hline Marks obtained in last exams & $\leq 60 \%$ & $279.0(79.90 \%)$ \\
\cline { 2 - 3 } & $>60 \%$ & \\
\hline
\end{tabular}

Table V. Association of Internet addiction with different factors.

\begin{tabular}{|c|c|c|c|c|}
\hline Variables & Categories & Addicted Number (\%) & Not-addicted Number (\%) & p value \\
\hline \multirow[t]{5}{*}{ Year of study } & 1st year & $6.0(8.20 \%)$ & $67.0(91.80 \%)$ & 0.091 \\
\hline & 2 nd year & $3.0(4.10 \%)$ & $70.0(95.90 \%)$ & \\
\hline & 3 rd year & $2.0(2.90 \%)$ & $67.0(97.10 \%)$ & \\
\hline & 4th year & $2.0(2.90 \%)$ & $67.0(97.10 \%)$ & \\
\hline & Interns & $8.0(12.30 \%)$ & $57.0(87.70 \%)$ & \\
\hline \multirow[t]{2}{*}{ Age } & $\leq 21$ years & $12.0(5.90 \%)$ & $193.0(94.10 \%)$ & 0.878 \\
\hline & $>21$ years & $9.0(6.20 \%)$ & $135.0(93.80 \%)$ & \\
\hline \multirow[t]{2}{*}{ Gender } & Male & $1.0(2.20 \%)$ & $44.0(97.80 \%)$ & 0.251 \\
\hline & Female & $20.0(6.60 \%)$ & $284.0(93.40 \%)$ & \\
\hline \multirow[t]{2}{*}{ Marital status } & Married & $0(0.0 \%)$ & $4.0(100.0 \%)$ & 0.611 \\
\hline & unmarried & $21.0(6.10 \%)$ & $324.0(93.90 \%)$ & \\
\hline \multirow[t]{2}{*}{ Marks obtained } & $\leq 60 \%$ & $13.0(18.60 \%)$ & $57.0(81.40 \%)$ & $<0.0001 *$ \\
\hline & $>60 \%$ & $8.0(2.90 \%)$ & $271.0(97.10 \%)$ & \\
\hline \multirow[t]{2}{*}{ Duration of Internet use } & $\leq 5$ years & $15.0(7.0 \%)$ & $198.0(93.0 \%)$ & 0.314 \\
\hline & $>5$ years & $6.0(4.40 \%)$ & $130.0(95.60 \%)$ & \\
\hline \multirow[t]{2}{*}{ Depression status } & Depressed & $13(17.3 \%)$ & $75.0(82.7 \%)$ & $<0.0001^{*}$ \\
\hline & Secure/ not-depressed student & $8.0(2.90 \%)$ & $274.0(97.10 \%)$ & \\
\hline
\end{tabular}

Statistical test applied: Chi square test

*Indicates statistical significant difference at $\mathrm{p} \leq 0.05$.

Table VI. Logistic regression analysis [Enter method] with Internet addiction as dependent factor to identify the strength of association.

\begin{tabular}{lllll}
\hline Variables & Categories & Adjusted Odds ratio & 95\%Confidence Interval (Upper-Lower) & p value \\
\hline Depression status & Depressed & 6.00 & $2.29-15.67$ & $<0.0001 *$ \\
\hline Marks obtained & $\leq 60 \%$ & 6.71 & $2.56-17.54$ & $<0.0001 *$ \\
\hline
\end{tabular}

*Indicates statistical significant difference at $\mathrm{p} \leq 0.05$. 


\section{Discussion}

The present study was carried out with the objective to assess the prevalence of Internet addiction among dental university students and to determine if there is any relationship of excessive Internet use with depression and academic performance. Internet addiction was assessed using Youngs Internet addiction questionnaire. A number of epidemiological studies conducted by various authors have used this questionnaire to assess Internet addiction in University students in different parts of the world [18,19,20]. Depression was assessed using Becks depression scale which has been used previously in various epidemiological studies to assess depression level of university students $[18,19,20]$.

Researchers have reported that university students are considered the most vulnerable group in society to develop internet addiction [20,21]. The prevalence of youth internet addiction reported by different researchers varies across different areas of the world [22]. It has been found that the occurrence rate of internet addiction among adolescents ranged from $1.98 \%$ to $35.8 \%$ in western and non-western countries [23,24,25]. No significant differences were observed in the prevalence of internet addiction with the different academic years. The overall prevalence of internet addiction was found to be $6.00 \%$ among the dental university students. Similar findings were reported by Goel D et al. [11], in their study done on Indian adolescents. On the contrary, studies carried out by Frangos CC et al. [26], and Krishnamurthy S and Chetlapalli SK [27] have found a higher prevalence of internet addiction in the university students. The authors are of the opinion that due to the differences in sample size, research design and diagnostic criteria used by different studies, these variations might have occurred.

The mean internet addiction score was found to be $13.87 \pm 11.90$. A significant difference was observed in the mean internet addiction score with different academic years of dental studies. The mean internet addiction score was found to be maximum for 1st year. Similar findings were reported by Alzayyat et al. [28], who found that the first year students are more prone to internet addiction as they have extra leisure time and are more likely to participate in risk taking behavior which may contribute to development of internet compulsive behaviors

Besides these, a number of researchers have found Internet addiction to be associated with mental health problems $[29,30]$. In the present study, the prevalence of depression was found to be $21.50 \%$. A significant difference in the prevalence of depression was observed with different academic years of dental studies. The maximum prevalence of depression was found in third year followed by final years. The mean depression score was found to be $11.27 \pm 08.37$. A significant difference was observed in the mean depression score with different academic years of dental studies. The 4th year showed the maximum depression score followed by 3 rd year. A reason that the authors can cite for the 3 rd year and 4th year showing higher prevalence of depression and higher mean depression score is academic pressure and work overload. The third year students have just entered their clinical postings and patient completion quota on time may put them under intense pressure. The final year are under high academic pressure as they have to complete the syllabus of eight subjects in order to clear their university exams which adversely affects their mental health and makes them more prone to depression.

Primary methods of internet use were through mobile phones followed by personal computers. The majority of the students were using mobile phones to access the internet. The number of students who were using University computers was very small. This can be explained by the fact that with the discovery of smart phones and better services offered by the network companies most students access internet from their phones due to ease of access and availability. There are no filters involved which enable them to surf different websites without filtration or time restrictions. Similar findings were reported by Alzayyat et al. [28], in his study done in Jordanian students.

Chatting followed by social networking was the main purpose for internet use. Similar findings were reported by Ozcan and Buzlu. [21], and Alzayyat et al. [28], who found that university students mainly use internet for chatting and personal communications. The use of internet for academic purposes is very low and needs to be enhanced.

Logistic regression analysis was performed to identify the strength of association. Results showed that depression status and academic performance were significantly associated with Internet addiction. The students who were depressed were more likely to be Internet addicted than secure/ not-depressed students. Similar findings were reported in previous studies carried out by Alzayyatet al. [28], Yang et al. [31]. The authors are of the opinion that students who have depressive symptoms usually seek internet for socializing with distant friends and short term relief which makes them addicted to internet. Hence, dental university should focus on identifying such high risk groups and provide psychological counseling to improve their mental health.

Also, individuals who scored $<60 \%$ marks were more likely to be addicted to Internet than students who scored $>60 \%$ marks. The studies done by $\mathrm{Ko} \mathrm{CH}$ et al. [13], Young KS et al. [15] have found that adolescents' addiction to the Internet has resulted in many negative consequences including academic failure, poor family relationships, impaired social functioning, emotional problems, and psychiatric problems. In a study carried out by Haque $M$ et al. [32], among medical university students in Malaysia, it was found that over $50 \%$ of the students either frequently or occasionally declared that their academic and job performance was affected because of Internet use. The 
authors are of the opinion that individuals who score $<60 \%$ marks are probably spending lot of time on Internet for socializing and chatting. They are not using it for academic purposes, therefore their academic performance is affected. Hence, efforts need to be made to counsel the students regarding the proper use of Internet for academic purposes.

Some of the limitations of the study include cross sectional nature of the study design. The study was carried out in a single institution; hence generalizing the results can be questionable. Besides, the identified risk factors there might be other risk factors which were not evaluated in this study. There are chances for social desirability bias wherein students in order to impress the investigator may not have reported exact values for Internet use and depression. Hence, further longitudinal studies involving students from various other dental institutions must be included before the results can be generalized.

\section{Conclusion}

The prevalence of Internet addiction was found to be $6.0 \%$. The mean internet addiction score was found to be maximum for 1st year followed by final year. Primary methods of internet use were through mobile phones followed by personal computers. Chatting followed by social networking was the main purpose for internet use. The prevalence of depression was found to be $21.50 \%$. The 4th year showed the maximum depression score followed by the 3rd year. The depression status and academic performance were significantly associated with Internet addiction. The university should provide psychological counseling to prevent Internet addiction in order to improve the mental status and academic performance of the students.

\section{References}

1. ITU-Istanbul Technical University. (2005). Internet host data: Network Wizards. RIPE.

2. Ni X, Yan H, Chen S, Liu Z. Factors influencing internet addiction in a sample of freshmen university students in China. Cyberpsychol Behav. 2009;12(3):327-330.

3. Tak SY, Park YS, and Kim E. Cyber delinquency among University students: With specific focus on human relationship, moral disengagement, personality, and general delinquency. The Korean Journal of Educational Psychology. 2007;21:799-826.

4. Montgomery K. Youth and digital media: a policy research agenda. J Adolesc Health. 2000;27(2 Suppl):61-68.

5. Beard KW. Internet addiction: a review of current assessment techniques and potential assessment questions. Cyberpsychol Behav. 2005;8:7-14.

6. Shek DTL, Sun RCF, Yu L. Internet addiction. In: Pfaff DW, Martin E, Pariser E (eds). Neuroscience in the 21st century. New York: Springer; 2013, pp $2775 \mathrm{e} 2811$.

7. Shek DT, Yu L. Internet addiction in Hong Kong adolescents: profiles and psychosocial correlates. Int J Disabil Hum Dev. 2012;11:133-142.

8. Widyanto L, Griffiths M. Internet addiction: A critical review. International Journal of Mental Health and Addiction. 2006;4(1):31-51.
9. Bakken IJ, Wenzel HG, Götestam KG, Johansson A, Oren A. Internet addiction among Norwegian adults: a stratified probability sample study. Scand J Psychol. 2009;50(2):121-127.

10. Christakis DA, Moreno MM, Jelenchick L, Myaing MT, Zhou C. Problematic internet usage in US college students: a pilot study. BMC Med. 2011;9:77. doi: 10.1186/1741-7015-9-77.

11. Goel D, Subramanyam A, Kamath R. A study on the prevalence of internet addiction and its association with psychopathology in Indian adolescents. Indian J Psychiatry. 2013;55:140-143.

12. Caplan SE. Preference for online social interaction: A theory of problematic Internet use and psychosocial well-being. Communication Research. 2003;30:625-648.

13. Ko CH, Yen JY, Chen CC, Chen SH, Yen CF. Proposed diagnostic criteria of Internet addiction for adolescents. J Nerv Ment Dis. 2005;193:728-733.

14. Young KS. Psychology of computer use: XL. Addictive use of the Internet: a case that breaks the stereotype. Psychol Rep. 1996;79(3 Pt 1):899-902.

15. Young KS. Cognitive behavior therapy with Internet addicts: treatment outcomes and implications. Cyberpsychol Behav. 2007;10:671-679.

16. Widyanto L, McMurran M. The psychometric properties of the internet addiction test. Cyberpsychol Behav. 2004;7:443-450. 17. Beck AT, and Steer RA. Beck Depression Inventory manual. San Antonio, TX: 1978. The Psychological Corporation.

18. Bahrainian SA, Alizadeh KH, Raeisoon MR, Gorji OH, Khazaee A. Relationship of Internet addiction with selfesteem and depression in university students. J Prev Med Hyg. 2014;55(3):86-89.

19. Senormancı O, Saraçlı O, Atasoy N, Senormancı G, Koktürk F, Atik L. Relationship of Internet addiction with cognitive style, personality, and depression in university students. Compr Psychiatry. 2014;55(6):1385-1390.

20. Dalbudak E, Evren C. The relationship of Internet addiction severity with Attention Deficit Hyperactivity Disorder symptoms in Turkish University students; impact of personality traits, depression and anxiety. Compr Psychiatry. 2014;55(3):497-503.

21. Ozcan NK, Buzlu S. Internet use and its relation with the psychosocial situation for a sample of university students. Cyberpsychol Behav. 2007;10(6):767-772.

22. Beard KW. Internet addiction: a review of current assessment techniques and potential assessment questions. Cyberpsychol Behav. 2005;8(1):7-14.

23. Aboujaoude E, Koran LM, Gamel N, Large MD, Serpe RT. Potential markers for problematic internet use: a telephone survey of 2,513 adults. CNS Spectr. 2006;11(10);750-755.

24. Niemz K, Griffiths M, Banyard P. Prevalence of pathological Internet use among university students and correlations with self-esteem, the General Health Questionnaire (GHQ), and disinhibition. Cyberpsychol Behav. 2005;8(6):562-570.

25. Johansson A, Götestam KG. Internet addiction: characteristics of a questionnaire and prevalence in Norwegian youth (12-18 years). Scand J Psychol. 2004;45(3): 223-229.

26. Frangos CC, Frangos CC, Sotiropoulos I. Problematic Internet Use among Greek university students: an ordinal logistic regression with risk factors of negative psychological beliefs, pornographic sites, and online games. Cyberpsychol Behav Soc Netw. 2011;14(1-2):51-58.

27. Krishnamurthy S, Chetlapalli SK. Internet addiction: Prevalence and risk factors: A cross-sectional study among college students in Bengaluru, the Silicon Valley of India. Indian 


\section{Mental Health}

J Public Health. 2015;59(2):115-121.

28. Alzayyat A, Al-Gamal E, Ahmad MM. Psychosocial correlates of Internet addiction among Jordanian university students. J Psychosoc Nurs Ment Health Serv. 2015;53(4):43-51.

29. Naseri L, Mohamadi J, Sayehmiri K, Azizpoor Y. Perceived Social Support, Self-Esteem, and Internet Addiction among Students of Al-Zahra University, Tehran, Iran. Iran J Psychiatry Behav Sci. 2015 Sep;9(3):e421. doi: 10.17795/ijpbs-421.

30. Bibbey A, Phillips AC, Ginty AT, Carroll D. Problematic Internet use, excessive alcohol consumption, their comorbidity and cardiovascular and cortisol reactions to acute psychological stress in a student population. J Behav Addict. 2015;4(2):44-52. 31. Yang CY, Sato T, Yamawaki N, Miyata M. Prevalence and risk factors of problematic Internet use: a cross-national comparison of Japanese and Chinese university students. Transcult Psychiatry. 2013;50:263-279.

32. Haque M, Rahman A, Majumder A, Haque SZ, Kamal ZM, Islam $\mathrm{Z}$, et al. Internet use and addiction among medical students of Universiti Sultan Zainal Abidin, Malaysia. Psychol Res Behav Manag. 2016;9:297-307. 